\title{
In memory of Professor Raffaele Casciaro
}

\author{
Giovanni Garcea
}

Published online: 12 October 2020

(C) Springer Nature B.V. 2020

\begin{abstract}
It is with profound sadness that we share the news that Prof. Raffaele Casciaro passed away on 27 July 2020. He is buried in his beloved Rossano, a small city in southeast Italy, where he was born in 1943. It is not easy to describe, in just a few sentences, the extraordinary human and scientific personality of Raffaele. He was an unattainable model to imitate, a mentor and a friend not only for us, but also for many other colleagues from outside the computational mechanics group of the University of Calabria. He left an indelible mark on the professional and personal lives of all of us and his absence arouses a deep sense of emptiness. We attempt to describe the scientific character of Raffaele and what he symbolizes to those who knew him and held him in high esteem.
\end{abstract}

\section{Scientific activity}

After a short research period in Rome "La Sapienza", where he earned his master degree in civil engineering (1967), he moved to the University of Calabria

G. Garcea $(\bowtie)$

Dipartimento di Ingegneria Informatica, Modellistica, Elettronica e Sistemistica, University of Calabria, Rende, CS, Italy

e-mail: giovanni.garcea@unical.it
(UNICAL) where he spent his entire academic career life. In 1972 Raffaele became Assistant Professor at the chair of "Scienza delle Costruzioni" (Solid and Structural Mechanics) and in 1988 Full Professor in the same field.

His scientific interests, since the early 1970s, were focused on computational mechanics. Raffaele foresaw the great potential of computational mechanics which, he believed, have played a key role in structural analysis and in the related research activities. It is worth noting that, at that time, computers were used only in the major research centers or university laboratories and their computational power, memory and software capabilities were incomparably lower than those we have today. Based on his belief, he became one of the pioneers and founders of the Italian Group of Computational Mechanics. In the late 1980s, he gave a significant contribution to establishing a PhD course in "Computational Mechanics" at UNICAL, which was the first in Italy in this research area and with this name. Over the years, this course has attracted many young students, most of whom are now researchers or professors at Italian and overseas universities.

Raffaele (Fig. 1) was an outstanding Italian researcher of his time. His scientific activities have always been aimed at developing structural models and numerical methods for simulating the mechanical behavior of structures. In doing that he firmly believed that research must be driven by practical problems. 


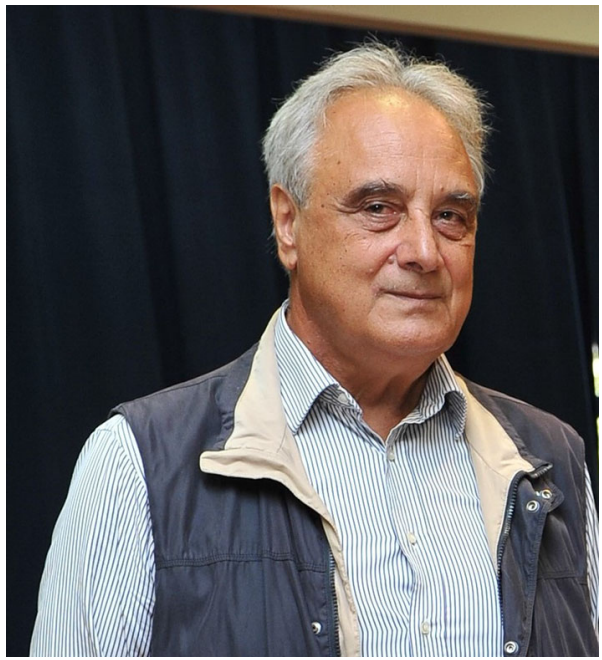

Fig. 1 A recent picture of Raffaele

His scientific contributions have covered variety of topics: limit and shakedown analysis, structural dynamics, nonlinear analysis of slender structures prone to buckle, modeling of geotechnical problems, solution algorithms for nonlinear problems, nonlinear structural models and their finite element formulations, multigrid methods, modeling of masonry and reinforced concrete structures.

His initial work, which already shows some of the ideas that would have inspired Raffaele's more mature scientific contributions, began in the early 1970s. This period can be considered as the "Stone Age" of the computer revolution in structural mechanics. Following the common practice of the Italian community of Scienza delle Costruzioni back then, his initial research cannot be easily found in international databases and is mainly published in internal reports or as conference papers.

Among his first works, Raffaele published a paper in collaboration with Di Carlo [1] dealing with the limit analysis of plates reformulated as a min-max problem using two different finite elements in which both stresses and displacements are interpolated. The development of this work afterwards produced, among others, a paper in collaboration with Cascini [2], which is considered a fundamental work in the literature of the field. The use of direct methods for the solution of limit analysis (and shakedown) problems and the advantages of using mixed finite elements in plasticity, where the accuracy of stress interpolation is preserved by the use of an element integration of the constitutive laws, are topics that Raffaele deeply investigated in the following years with notable scientific contributions.

In the late 1970s, at a conference, Raffaele met Eduard Riks with whom he established a relationship of mutual respect and friendship. Inspired by Riks' work, Raffaele started studying plasticity and other nonlinear problems using incremental arc-length methods. The arc-length formulation for the analysis of slender structures was significantly strengthened by a proposal of Raffaele and his coworkers of the late 1990s, which was highly appreciated by Riks himself. In that work, the use of a mixed description in stress and displacement is proposed, where stresses are taken as primary variables in both the predictor and corrector states of the iterative scheme. This solution outperformed standard displacement descriptions in terms of robustness and efficiency. Moreover, the Riks pathfollowing analysis was generalized, years afterwards, by other important research contributions of Raffaele. Among the others, it was adopted as a strategy for solving the optimization problem deriving from the static shakedown theorem and for handling the unstable static response of softening materials in masonry walls.

In the late 1970s, in collaboration with Di Carlo, Pignataro and Aristodemo, he started working on a mile-stone of his research activity, namely the finite element implementation of Koiter's theory of elastic stability. Raffaele had followed some of Koiter's lectures which had had a deep impact on him. He immediately foresaw the potentialities of a finite element formulation of this theory for designing slender structures prone to buckle. It resulted into an innovative tool able to efficiently estimate the initial post-critical behavior of elastic slender structures taking into account the imperfection sensitivity also in case of almost coincident buckling loads. The initial work, although containing notable contributions, was mainly presented at conferences or in internal reports $[3,4]$, while the first international paper on the topic was only published some years later [6]. To that period also belongs a work where the need of a geometrically exact structural model in Koiter analysis is discussed and highlighted [5]. In the subsequent years Raffaele and his research group developed the method into a consolidated analysis and design tool which paved the way for current researches dealing with the optimization of aerospace composite structures. 
Another important work of this initial period regards the incremental step-by-step methods used for the dynamic analysis of elasto-plastic structures [7]. Throughout his career life, Raffaele gave a large contribution to developing methods and algorithms for seismic analysis and design of reinforced concrete and masonry structures. These works, many of them unfortunately never published, inspired many of his students and collaborators to found software houses in Calabria, which directly uses Raffaele's efficient algorithms. Among the non-published results, we would particularly like to remember a set of highperforming linear algebra routines, extensively used through the years by Raffaele's whole research group.

\section{Teaching activity}

Raffaele's human profile is strongly reflected not only in his research work, but also in his teaching activity. He communicated with passion and irony. His lessons, never ordinary, and which often ended far beyond the scheduled time, were full of food for thought.

Raffaele knew how to communicate complex and advanced topics in an simple and synthetic way, making them accessible even to a non-specialized audience. His teaching always focused on the general rules governing solid and structural mechanics avoiding any notional aspects. His modern and unconventional lessons, his great charisma among students, his originality as a teacher, inspired a great number of students to undertake research and attend the $\mathrm{PhD}$ program. With his lessons he trained a generation of engineers who, still today, maintain a deep and clear sign of his teaching. We think this shows Raffaele's success as a great teacher.

Raffaele's course of Scienza delle Costruzioni can be considered, even today, a modern and unconventional approach to the basics of solid and structural mechanics. It was attended by all students of civil engineering from the academic year 1986/1987 until his retirement (2013). The populatity of Raffaele among students was enormous and, as usually occurs in these cases, a series of anecdotes led to his fascinating charismatic image. He was able to communicate every argument using a unified approach that gave a simple view of the essential aspects of the topic, be it the classic elastic theory, plasticity, limit analysis or structural stability. In line with his view of teaching, the final exam was based on unconventional questions, requiring a deep and overall understanding of the course topics.

Another important course, given by Raffaele from the late 1970s, was Teoria delle strutture (Theory of Structures). It was, at least until the middle of the 1990s, an optional course attended by a few, highly motivated, students. The topics were treated with a clear computational mechanics approach for the analysis of real-life structures discretized with the finite element method. The course topics ranged from simple problems of linear analysis to more advanced arguments such as path-following methods applied to plasticity and large deformation analysis and Koiter method for buckling problems. During his lessons, Raffaele used to write entire sections of codes in Pascal on the blackboard, most of the time without compiling errors. The course was way ahead of its time. At that time, computers were unknown to most of the people and expensive, so that student should work in the "computer center" of UNICAL to develop codes. Notwithstanding these difficulties, all those who attended Raffaele's course were aware of learning something unique among the Italian universities and enthusiastic about being introduced into a fascinating modern world by an expert and brilliant guide.

Due to the originality of Raffaele's presentations, many of his students encouraged him to write a book collecting his lectures. Unfortunately, only in the recent years "he had more free time", as he used to say, to write a book. This is almost complete and we hope will be published soon.

\section{Working with Raffaele}

Raffaele loved working with other people, especially with young researchers. He used to spend many hours in programming, working side by side with master or $\mathrm{PhD}$ students. He truly believed that this was the correct way to quickly transfer knowledge he had acquired over the years to younger researchers, allowing them to deal with complex problems.

The exchange of views and ideas, often carried out through long technical discussions in front of a blackboard, was for him the most effective way to advance the research process, which benefited from his brilliant intuition. Young researchers loved him because of his profound generosity, his never giving 
up and the support he gave to everyone in facing the difficulties.

Intelligence and intuition were the best Raffaele's qualities. His capacity to deeply explore new topics in a few minutes, after short technical discussions or presentations, was impressive and amazing at the same time. He had the ability to eliminate, from a complex problem, all the redundant details, thereby focusing on its main logical scheme. In this way, using few theoretical concepts, he was often able to detect weaknesses or strengths in topics far from his specific skills. There are many examples which highlight Raffaele's great intuition. We recall the case of an affirmed researcher, Angelo Miele, who presented the results of his research group regarding the optimization of airplanes flying trajectory at UNICAL. Raffaele made a comment and the speaker, surprised, said "You have understood in a few minutes what we have learned in years of hard work". This ability made Raffaele's questions at conferences very popular. Since he interpreted research activity with extreme seriousness, his frequent questions and objections after presentations were always driven by an innate curiosity and scientific integrity.

Raffaele did not like research work on what he called "trendy topics" which, he said, led to the writing of papers without making any substantial contributions to knowledge. Also, he disliked research dealing with ad-hoc constructed problems, which do not have real-life implications. For these reasons, he was critical regarding the rules used in recent years for recruiting and promoting Italian professors. In Raffaele's opinion, these rules favored a distorted use of the research activity, which became more a tool for speeding-up academic carriers rather than something beneficial for society. He often said that Italian scientific community had fallen ill with "articolite" (in Italian articolo means paper and the suffix ite stands for the associated illness). However, his criticism should not be misunderstood. Raffaele did encourage research and the publication of papers with substantial scientific contributions and real-life implications.

Raffaele was not only a brilliant researcher but also a sophisticated intellectual who had a broad culture that included several interests in the humanities: history, music and literature. He was able to discuss a wide range of subjects and to choose these according

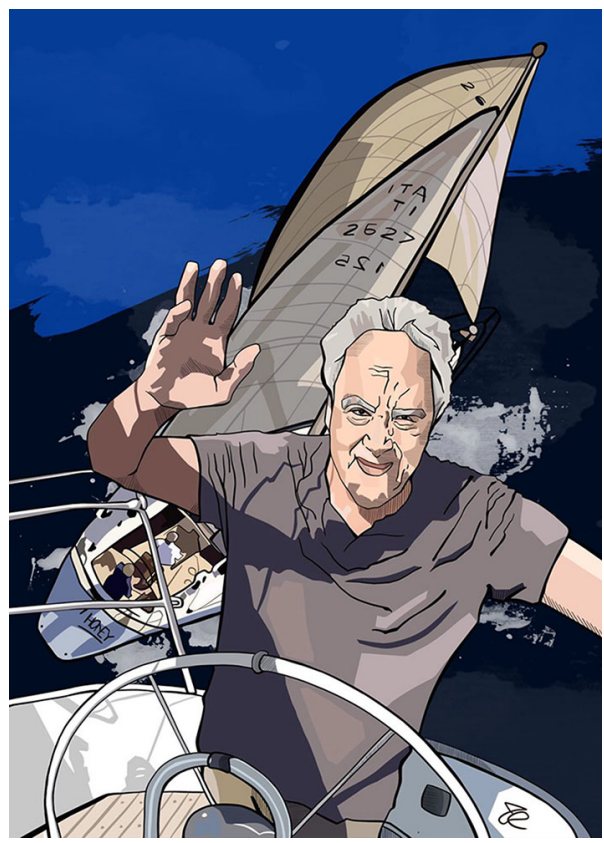

Fig. 2 A portrait showing Raffaele on his boat

to the public audience. He was entertaining with a good sense of humor and irony (Fig. 2).

Raffaele left a memorable mark on all of us and we find fragments of him in the most unpredictable aspects of our lives. However, it is his way of being a professor influences us the most. University was his home for almost his entire life, the place where he followed his passion for doing high level research and creating a solid group of researchers who shared this purpose.

Acknowledgements We would like to thank Maurizio Aristodemo and Giovanni Formica for suggestions they gave for writing this memory.

\section{Compliance with ethical standards}

Conflict of interest The authors declare that they have no conflict of interest.

\section{References}

1. Casciaro R, Di Carlo A (1970) Formulazione dell'analisi limite delle piastre come minimax, Giornale del Genio Civile, fascicolo 5, nota I (Feb 1970) e nota II (May 1970)

2. Casciaro R, Cascini L (1982) A mixed formulation and mixed finite elements for limit analysis. Int J Numer Methods Eng 18(2):211-243 
3. Casciaro R, Di Carlo A, Pignataro M (1976) A finite element tecnique for bifurcation problems, Internal Report University of Rome "La Sapienza", N. II-192

4. Casciaro R, Aristodemo M (1977) Perturbation analysis of geometrically nonlinear structures, paper presented at conference Finite Elements in Nonlinear Solid and Structural Mechanics, Geilo (Norway)

5. Pignataro M, Di Carlo A, Casciaro R (1982) On nonlinear beam models from the point of view of computational postbuckling analysis. Int J Solids Struct 18(4):327-347
6. Casciaro R, Lanzo AD, Salerno G (1992) Finite element asymptotic analysis of slender elastic structures: a simple approach. Int J Numer Methods Eng 35(7):1397-1426

7. Casciaro R (1975) Time evolutional analysis of nonlinear structures. Meccanica 10:156-167

Publisher's Note Springer Nature remains neutral with regard to jurisdictional claims in published maps and institutional affiliations. 